\title{
Description of the volatile fraction of Erica honey from the northwest of the Iberian Peninsula
}

\author{
M. Shantal Rodríguez-Flores ${ }^{\mathrm{a}}$, Soraia I. Falcão ${ }^{\mathrm{b}}$, Olga Escuredo ${ }^{\mathrm{a}, *}$, M. Carmen Seijo $^{\mathrm{a}}$, \\ Miguel Vilas-Boas ${ }^{\mathrm{b}}$ \\ ${ }^{\text {a }}$ Facultad de Ciencias, Universidad de Vigo, Campus As Lagoas, Ourense, Spain \\ ${ }^{\mathrm{b}}$ Centro de Investigação de Montanha (CIMO), Instituto Politécnico de Bragança, Campus de Santa Apolónia, Bragança, Portugal
}

\section{A R T I C L E I N F O}

\section{Keywords:}

VOCs

Honey

Erica

Palynological analysis

GC-MS

SPME

\begin{abstract}
A B S T R A C T
Heather honey is highly appreciated by consumers for its sensorial profile, which varies depending on the flora used by the honeybees. Volatile compounds contribute to these qualities. Characterisation of the volatile profile related to the botanical origin is of great interest for the standardization of unifloral honey. For this reason, 33 heather honey samples from northwest of the Iberian Peninsula were analysed by headspace solid-phase microextraction (HS-SPME) to identify the key volatile compounds in this type of honey. The aim of this research was to provide a descriptive analysis of these compounds, and to find whether there is any relationship with the main Erica species. A total of 58 volatile organic compounds were found, with hotrienol, phenylacetaldehyde, and cis-linalool being the most abundant. A principal component analysis and Spearman's rank correlation showed the homogeneity of the volatile profile in the samples, and their close relationship with the main pollen types.
\end{abstract}

\section{Introduction}

The production of honey and other apicultural products is an ancient activity with economic importance worldwide (Manyi-Loh, Ndip \& Clarke, 2011). Honey, the most important primary food of beekeeping derived from nectar and/or honeydew, contains sugars as a major component. However, it has also some valuable nutrients, such as vitamins, minerals, enzymes, flavouring organic compounds, free amino acids and numerous volatile compounds, as minor components (Manyi-Loh et al., 2011; Escuredo, Míguez, Fernández-González \& Seijo, 2013). The composition of honey and its sensorial properties are strongly associated with the plants visited by the honeybees and its geographical origin, since the climate and soil determine the distribution of the plants (Castro-Vázquez, Díaz-Maroto, De Torres \& PérezCoello, 2010; Manyi-Loh et al., 2011).

The Northwest of the Iberian Peninsula is an important area of production of heather honey. Several different species of Erica plants contribute to the production of this honey type, especially Erica umbellata, E. arborea, and E. cinerea, among others. These plants are very abundant in mountainous areas and form monospecific scrublands or, together with other plants such as Ulex, Cytisus and Genista, mixed plant formations, which are very well represented in the area (Seijo \& Jato,
1998; Rodríguez-Flores, Escuredo, Seijo-Rodríguez \& Seijo, 2019). The honey obtained from these plants has sensorial properties that are highly appreciated by consumers. These include a dark amber to dark colour with reddish tones, persistent and slightly bitter taste, and vegetal smell reminiscent of wet soil or wet leaves in soil, sometimes with floral perceptions.

The volatile profile is one of the most important characteristics of a food product, since it has a notable influence on the organoleptic profile and supports its authenticity (Radovic, Careri, Mangia, Musci, Gerboles \& Anklam, 2001). The volatile substances in honey form a complex mixture that depends on the source area, nectar, processing and storage conditions, and the action of honeybees and microorganisms (CastroVázquez, Díaz-Maroto, González-Viñas \& Pérez-Coello, 2009; Escuredo, Dobre, Fernández-González \& Seijo, 2014; da Silva, Gauche, Gonzaga, Costa \& Fett, 2016). Although many volatile compounds can be found in the honey samples, some of them are specific, giving certain honeys a particular fingerprint. In fact, specific markers for honey types are being investigated. For this reason, the characterisation of the volatile compounds of honey is a topic of great interest in beekeeping, since it can contribute to the discrimination and characterisation of the product (Karabagias, Papastephanou \& Karabagias, 2019).

According to previous studies, more than 600 different compounds

\footnotetext{
* Corresponding author.

E-mail address: oescuredo@uvigo.es (O. Escuredo).
} 
have been identified in the volatile fraction of honey (Cuevas-Glory, Pino, Santiago \& Sauri-Duch, 2007; Kaškonienè \& Venskutonis, 2010; Manyi-Loh et al., 2011). However, the number of these identified compounds is likely to increase, since there are unifloral honeys that have not yet been characterized by their volatile composition, and due to the continuous improvement of the sensitivity of the techniques of analysis. Additionally, the extraction method plays an important role in the quantification and identification of volatile compounds. An association of both main techniques, GC (gas chromatography) and MS (mass spectrometry), results in a combined GC-MS technique that allows the separation and identification of complex mixtures. This technique is a powerful tool to separate, identify, and quantify volatile and semi-volatile components. However, the methods for the extraction of volatile components are prone to sample loss and degradation, and require many steps and a lot of time. Solid-phase microextraction (SPME) can eliminate these problems. This is a relatively new, rapid, solvent-free extraction technique that can be used with GC (Arthur \& Pawliszyn, 1990). Its straightforward handling makes it perfect for working with a matrix as complex as the volatile substances of honey (Cuevas-Glory et al. 2007).

Normally, unifloral honey has more uniform volatile profiles compared to multifloral honey. Several studies have tried to characterize unifloral honey of various origins by determining their volatile profiles, in search of specific chemical marker compounds (Castro-Vázquez et al., 2009; de la Fuente, Martínez-Castro \& Sanz, 2005; Guyot, Scheirman \& Collin, 1999; Kaškonienè \& Venskutonis, 2010; Manyi-Loh et al., 2011; Piasenzotto, Gracco \& Conte, 2003). Previous studies on heather honey from Erica arborea described volatile compounds such as $\alpha$-isophorone, 2-hydroxy-3,5,5-trimethylcyclohexanone, furfuryl alcohol, benzyl alcohol and 2-phenylethanol (de la Fuente et al., 2005; Kaškonienè \& Venskutonis, 2010; Karabagias, Maia, Karabagias, Gatzias \& Badeka, 2018).

Heather honey from the northwest of the Iberian Peninsula comes mainly from Erica umbellata and E. arborea, but honeybees can use other Erica species to produce honey. Due to the influence of volatile compounds on the sensory properties of honey, a detailed investigation of the volatile profile of heather honey could contribute to its characterisation. Thus, this work aims to study the compounds of the volatile fraction of heather honey from the northwest of the Iberian Peninsula, and their relationship with the surrounding flora.

\section{Materials and methods}

\subsection{Honey samples}

A total of 33 fresh heather honeys produced in the northwest of the Iberian Peninsula (Spain and Portugal) were provided directly by the beekeepers. Samples were obtained during the 2018 and 2019 harvests. The extractions were carried out on fresh samples. These were kept frozen during storage until the volatile extraction date. Melissopalynology was used to confirm the botanical origin of the samples.

\subsection{Palynological analysis}

The qualitative palynological study of the honey samples was performed according to the method used in Rodríguez-Flores, Escuredo, Seijo-Rodríguez, \& Seijo, (2019). Ten grams of honey were dissolved in double distilled water and centrifuged at $4500 \mathrm{rpm}$ for $10 \mathrm{~min}$. The obtained sediment was re-dissolved and centrifuged for an additional $5 \mathrm{~min}$. The final volume of the sediment was used to prepare a slide for the microscopic study. The different pollen types and their relative frequencies (pollen spectra of the honey sample) were determined using a Nikon Optiphot II microscope (Nikon UK Ltd., London, UK) at 400x or 1000x (when needed). The results were expressed as the percentage of the pollen type over the total pollen counted and identified in the sample.

\subsection{Volatile extraction by solid phase microextraction (SPME)}

A $7.5 \mathrm{~g}$ honey sample was introduced into a $20 \mathrm{~mL}$ vial, before adding $7.5 \mathrm{~mL}$ of a $30 \%$ sodium chloride solution. After placing a magnetic stirrer, the vial was sealed. Then, the sample was stirring until homogenisation was achieved and placed into a thermostatic bath at $50{ }^{\circ} \mathrm{C}$. A $65 \mu \mathrm{m}$ thick polydimethylsiloxane/divinylbenzene (PDMS/ DVB) fiber (Supelco SPME fibre 57326U, Darmstadt, Germany) was used for the extraction and subsequent analysis of the volatile compounds by SPME. Before use, the SPME fiber was preconditioned and thermally cleaned. This was done thermally by exposing the fiber to a conditioning temperature of $250{ }^{\circ} \mathrm{C}$ for $50 \mathrm{~min}$ in the GC injection port. The chosen extraction mode was Headspace (HS), since the analytes of interest were highly volatile. Thus, the fiber was introduced into the vial and exposed to the headspace under the sample for $60 \mathrm{~min}$. After this period, the fibre was retracted and transferred to the gas phase chromatograph (GC) injector, where the compounds were desorbed for $5 \mathrm{~min}$.

\subsection{Chromatographic analysis by GC-MS}

The analysis of volatile compounds previously extracted by SPME was performed using a GC-MS Perkin Elmer System with a GC module Claurus $^{\circledast} 580$ GC and an MS Claurus ${ }^{\circledast}$ SQ 8 S module (PerkinElmer Inc., Massachusetts, USA). The injection was made in splitless mode, and the fibre desorption was carried out for $5 \mathrm{~min}$ at $250{ }^{\circ} \mathrm{C}$. The compounds were separated on a DB-5MS column $(30 \mathrm{~m} \times 0.25 \mathrm{~mm}$ i.d., thickness $0.25 \mathrm{um} ; \mathrm{J} \& \mathrm{~W}$ Scientific, Inc.). The oven temperature was programmed from $40{ }^{\circ} \mathrm{C}$ to $170{ }^{\circ} \mathrm{C}\left(3{ }^{\circ} \mathrm{C} / \mathrm{min}\right)$ and from $170{ }^{\circ} \mathrm{C}$ to $290{ }^{\circ} \mathrm{C}$ $\left(25{ }^{\circ} \mathrm{C} / \mathrm{min}\right.$ ), then was maintained at $290{ }^{\circ} \mathrm{C}$ for $15 \mathrm{~min}$. Helium was used as carrier gas at a constant velocity of $40 \mathrm{~cm} . \mathrm{s}^{-1}$. The mass spectrum was obtained from an ionization energy of $70 \mathrm{eV}$. The transfer line and the ionization source temperatures were $250{ }^{\circ} \mathrm{C}$ and $230{ }^{\circ} \mathrm{C}$, respectively. TurboMass Ver6.1.0 6.1 software (PerkinElmer Inc., Massachusetts, USA) was used to acquire the data. The assignment of the chromatographic peaks was performed using a commercial MS database (NIST 2011 mass spectral library). Linear retention indices (LRI) were calculated for each component detected. This allowed us to confirm the identification of each compound. For the calculation of the LRI indices, a mixture of $n$-alkanes $\left(\mathrm{C}_{7}-\mathrm{C}_{40}\right)$ (Sulpelco, Bellefonte, PA, USA) dissolved in hexane was used. The values of the relative areas (percentage of total volatiles) were obtained directly from the total ion current chromatogram (Total Ion Chromatogram, TIC).

\subsection{Statistical analysis}

The data were analysed using the statistical programs IBM SPSS Statistics 23.0 (IBM, UK) and STATGRAPHICS Centurion XVIII (Statgraphics Technologies, Inc., Virginia, USA). Principal component analysis was carried out to show the homogeneity of the samples and relationships between the VOCs and the main pollen types. Furthermore, these relationships were corroborated by a Spearman's rank correlation. These correlation coefficients measure the strength of the association between the variables. The $P$-value shows the statistical significance of the estimated correlations.

\section{Results and discussion}

\subsection{Pollen spectra of the honey samples and predominance of Erica species}

The pollen profile of a honey sample commonly contains many pollen types from the flowering plants of the neighbourhood where honey was produced. Even if the sample is considered a unifloral honey, different pollen grains can appear, leading to a high biodiversity of 


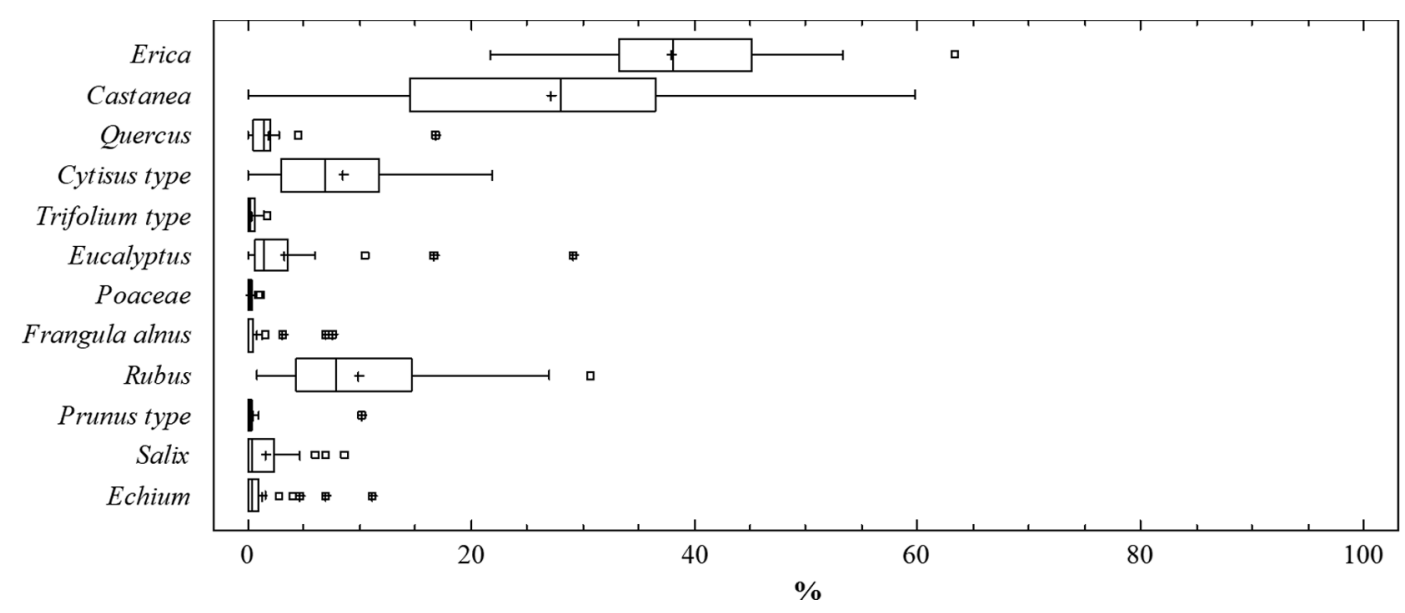

Fig. 1. Main pollen types found in heather honey samples with a percent of over $50 \%$

pollen types. In the studied honeys, 79 pollen types were identified. The most representative was Erica pollen, which was always present at a high percentage. The pollen of Castanea, Quercus, Cytisus type, Trifolium type, Eucalyptus, Poaceae, Frangula alnus, Rubus, Prunus type, Salix and Echium were the most representative in this group of honeys, found in more than $50 \%$ of the samples (Fig. 1). The average value of Erica pollen was $37.9 \%$, and the maximum value was $63.3 \%$. Erica pollen can appear in unifloral honey at values of $<45 \%$ (the considered value in melissopalynology for dominant pollen), as occurs with other plants of the Ericaceae family (Persano-Oddo, Piro, Bruneau, Guyot-Declerck, Ivanov, Piskulová \& Von der Ohe, 2004; Rodríguez-Flores et al., 2019; Tuberoso, Bifulco, Caboni, Cottiglia, Cabras \& Floris, 2009).

Castanea was the secondary pollen in most of the samples, with a mean value of $27.1 \%$ and a maximum value of $59.8 \%$. The values of Castanea pollen were considered for honey typification according to their overrepresentation in the pollen spectra of honey. Rubus was also identified in all the samples, and Cytisus type was present in $97 \%$ of the samples. Both were considered accompanying pollens, together with Eucalyptus. The pollens of Quercus, Salix, Echium, Frangula alnus, Prunus type, Trifolium type and Poaceae were also observed in more than 50\% of the samples. These pollen types are very common in the pollen spectra of honeys from this geographical region (Escuredo, FernándezGonzález \& Seijo, 2012; Escuredo et al., 2013).

Regarding the different Erica species identified through the palynological analysis of the honey, the main were E. umbellata, E. arborea and E. cinerea. Additionally, a group of other species of Erica, named Other Erica species, was distinguished. Table 1 shows the values corresponding to the predominance of the species and the main secondary pollen types in these group of samples. The highest mean percentages were $39.7 \%$ for the type other Erica and $34.8 \%$ for E. cinerea, while the mean value for E. umbellata was $29.1 \%$ and for E. arborea was $28.2 \%$. In all samples, Castanea and Rubus were present as secondary pollens. Furthermore, the Cytisus pollen type was found as a secondary pollen in samples with a predominance of $E$. arborea and E. umbellata. Finally, Eucalyptus was a secondary pollen in the honeys with a predominance of $E$. cinerea.

\subsection{Volatile fraction of heather honeys}

Honey has a high number of volatile organic compounds (VOC) found in very low concentrations (Jerković \& Kuś, 2014). These may appear as more or less complex mixtures of different functional groups. Some of these compounds were identified, like alcohols, carbonyl compounds, carboxylic acids, esters, phenols, monoterpenes, norisoprenoids, and benzene derivatives, among others.

As a result of this study, 58 volatile compounds from heather honey samples were identified. Table 2 shows the retention time (RT), the calculated Linear Retention Index ( $\left.{ }^{\mathrm{a}} \mathrm{LRI}\right)$, and the Linear Retention Index Theoretical ( ${ }^{\mathrm{b}} \mathrm{LRI}$ ) obtained through the NIST Chemistry Web Book for each compound, and the relative concentration (\%). Hotrienol was the main volatile compound detected in the SPME analysis for this honey type (Fig. 2), being represented in $82 \%$ of the samples. This compound was by far one of the compounds with the highest concentrations, with a mean value of $46 \%$, reaching a maximum value of $69 \%$. The presence of the compound hotrienol is common in floral scents and in several food products, including honey, and is typically

Table 1

Main pollen types according to the predominant Erica species.

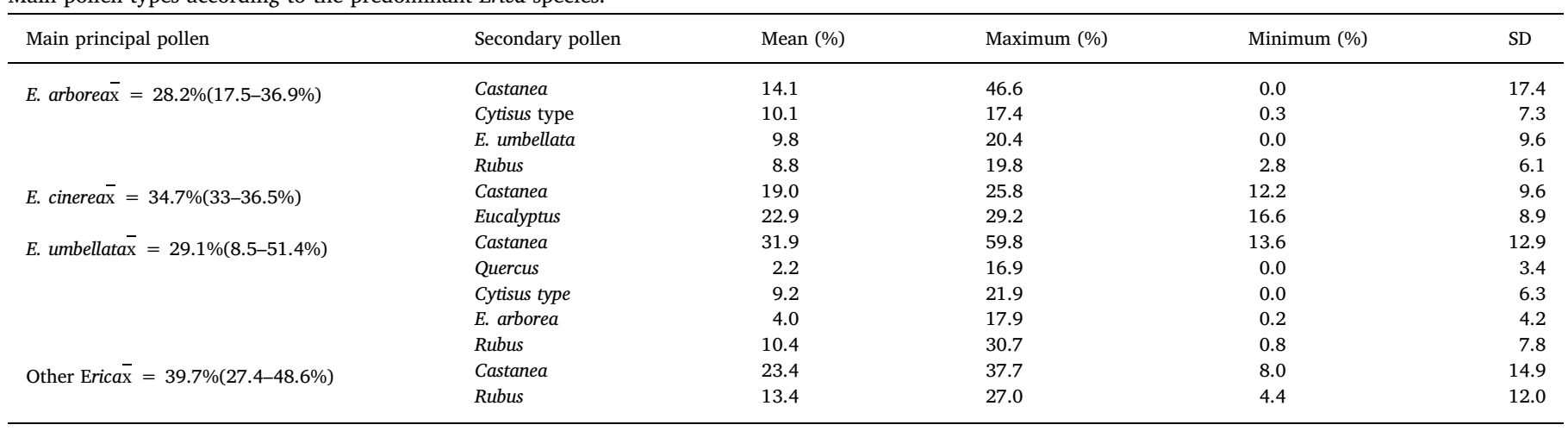

$\overline{\mathrm{x}}$ : arithmetic average; SD: standard deviation; Secondary pollen: Pollen types that appeared between 15 and $45 \%$ in honey samples 
Table 2

Main volatile compounds isolated by GC-MS (SPME) in heather honey samples.

\begin{tabular}{|c|c|c|c|c|c|c|c|}
\hline \multirow[t]{2}{*}{ Volatile compounds } & \multirow[t]{2}{*}{ RT (min) } & \multirow[t]{2}{*}{ a LRI } & \multirow[t]{2}{*}{ b'LRI } & \multicolumn{4}{|l|}{$\%$} \\
\hline & & & & Mean & $\operatorname{Max}$ & Min & SD \\
\hline Phenylacetaldehyde & 11.1 & 1043 & 1046 & 11.3 & 37.0 & 1.5 & 10.6 \\
\hline$\alpha$-methylbenzyl alcohol & 11.9 & 1061 & 1046 & 5.2 & 7.1 & 3.1 & 1.6 \\
\hline cis-Linalool oxide & 12.2 & 1068 & 1068 & 13.4 & 45.6 & 6.3 & 8.2 \\
\hline trans-Linalool oxide & 12.9 & 1085 & 1086 & 5.1 & 15.1 & 2.2 & 3.4 \\
\hline Methyl benzoate & 13.2 & 1092 & 1095 & 5.4 & 7.8 & 4.1 & 2.0 \\
\hline Hotrienol & 13.9 & 1108 & & 45.7 & 68.9 & 14.2 & 14.1 \\
\hline 2-Phenylethanol & 14.3 & 1117 & 1120 & 5.3 & 9.6 & 0.0 & 3.5 \\
\hline Isophorone & 14.4 & 1119 & 1124 & 4.0 & 8.3 & 1.4 & 2.8 \\
\hline 4-Oxoisophorone & 15.5 & 1143 & 1145 & 2.8 & 5.1 & 1.6 & 1.0 \\
\hline 3,6-dihydro-4-methyl-2-(2-methyl-1-propenyl)-2H-pyran & 15.7 & 1147 & 1147 & 2.0 & 3.7 & 1.2 & 0.8 \\
\hline Ethylbenzoate & 16.5 & 1165 & 1177 & 3.0 & 5.5 & 1.0 & 1.9 \\
\hline Methyl 2-Phenylacetate & 16.9 & 1174 & 1245 & 4.7 & 6.1 & 3.3 & 2.0 \\
\hline 2-methyl-2-Nonen-4-one, & 17.1 & 1178 & & 2.3 & 3.2 & 1.5 & 0.9 \\
\hline Safranal & 17.9 & 1196 & 1197 & 4.4 & 7.9 & 1.6 & 2.4 \\
\hline 2,6-dimethyl-3,7-octadiene-2,6-diol & 18.0 & 1198 & & 5.5 & 8.1 & 2.9 & 3.7 \\
\hline Decanal & 18.3 & 1205 & 1208 & 2.7 & 8.3 & 0.8 & 2.8 \\
\hline 3-Phenylfuran & 18.8 & 1216 & 1224 & 3.8 & 10.7 & 1.1 & 2.5 \\
\hline 2,3-Dihydrobenzofuran & 19.2 & 1224 & 1237 & 5.4 & 10.4 & 2.2 & 3.1 \\
\hline 1,4-dimethyl-2-octadecylcyclohexane & 19.7 & 1236 & & 0.8 & 1.0 & 0.7 & 0.2 \\
\hline Ethylphenyl acetate & 19.8 & 1238 & 1245 & 1.2 & 1.5 & 1.0 & 0.3 \\
\hline 4-methoxybenzaldehyde & 20.4 & 1251 & 1258 & 3.5 & 5.5 & 2.3 & 1.4 \\
\hline Thymol & 22.3 & 1293 & 1295 & 3.8 & 14.7 & 0.9 & 4.0 \\
\hline Decanoic acid, methyl ester & 23.6 & 1323 & 1322 & 4.6 & 6.5 & 2.7 & 2.7 \\
\hline 4-methyl-1-Naphthalenol, & 23.8 & 1327 & & 1.6 & 2.1 & 0.9 & 0.5 \\
\hline 1,1,5-trimethyl-1,2-dihydronaphthalene (TDN) & 24.5 & 1343 & 1354 & 8.0 & 21.2 & 0.6 & 7.4 \\
\hline 1-(2,6,6-trimethyl-1,3-cyclohexadien-1-yl)-2-buten-1-one & 25.7 & 1371 & & 2.1 & 5.4 & 0.1 & 1.5 \\
\hline$n$-Decanoic acid & 26.7 & 1394 & 1394 & 4.3 & 5.7 & 3.5 & 1.2 \\
\hline Ethyl decanoate & 26.8 & 1396 & 1403 & 2.2 & 2.8 & 1.7 & 0.6 \\
\hline 1,1,6-Trimethyl-1,2-dihydronaphthalene & 26.8 & 1396 & & 2.4 & 5.3 & 0.8 & 1.5 \\
\hline 1,6,6-Trimethyl-7-(3-oxo-but-1-enyl)-3,8-dioxatricyclo[5.1.0.0(2,4)]octan-5-one & 28.4 & 1434 & & 1.9 & 3.6 & 0.8 & 1.5 \\
\hline 5-Methyl-2-phenyl-2-hexenal & 29.3 & 1455 & 1488 & 1.1 & 1.6 & 0.6 & 0.5 \\
\hline$\gamma$-Decalactone & 29.6 & 1462 & 1490 & 5.7 & 13.0 & 1.6 & 3.0 \\
\hline 4,6,10,10-tetramethyl-5-oxatricyclo[4.4.0.01,4]dec-2-en-7-ol & 29.8 & 1467 & & 5.7 & 10.8 & 1.8 & 3.6 \\
\hline 4-(2,4,4-Trimethyl-cyclohexa-1,5-dienyl)-but-3-en-2-one & 30.0 & 1471 & & 1.3 & 1.4 & 1.1 & 0.2 \\
\hline$\delta$-Decalactone & 30.2 & 1476 & & 3.2 & 12.1 & 0.6 & 2.4 \\
\hline cis-2-hydroxy-1-(2-propenyl)-Cyclopentanecarboxylic acid, methyl ester & 30.2 & 1477 & & 6.8 & 9.2 & 4.5 & 3.3 \\
\hline Ethyl isoallocholate & 30.6 & 1480 & & 1.2 & 1.4 & 1.0 & 0.3 \\
\hline 1,3,5-trimethyl-2-octadecylcyclohexane (isomer 1 ) & 30.7 & 1489 & & 2.9 & 6.8 & 1.0 & 2.2 \\
\hline Tetradecane & 30.9 & 1494 & & 1.8 & 2.2 & 1.5 & 0.5 \\
\hline 2,3-Dimethyl-cyclohexa-1,3-diene & 31.3 & 1503 & & 4.1 & 8.6 & 1.2 & 1.8 \\
\hline 6-Camphenol & 31.3 & 1503 & 1109 & 3.0 & 3.7 & 2.1 & 0.7 \\
\hline Pentadecane & 31.4 & 1506 & & 1.0 & 1.3 & 0.8 & 0.3 \\
\hline 1,3,5-Trimethyl-2-octadecylcyclohexane (isomer 2) & 31.5 & 1508 & & 2.5 & 4.6 & 1.4 & 1.8 \\
\hline 1,7,7-Trimethylbicyclo $[2,2,1]$ hept-5-en-2-ol & 31.5 & 1508 & & 7.1 & 8.5 & 5.0 & 1.5 \\
\hline 3,7,7-Trimethyl-1-penta-1,3-dienyl-2-oxabicyclo[3.2.0]hept-3-ene & 32.3 & 1529 & & 5.7 & 26.2 & 1.1 & 4.9 \\
\hline Megastigmatrienone (Isomer1) & 33.0 & 1546 & & 2.4 & 2.4 & 2.3 & 0.1 \\
\hline Megastigmatrienone (Isomer2) & 33.7 & 1564 & & 7.4 & 10.5 & 2.9 & 2.9 \\
\hline$\delta$-Selinene & 34.4 & 1582 & & 0.8 & 1.0 & 0.5 & 0.2 \\
\hline 4,4-dimethyl-6-ethyl-3,4-dihydrocoumarin & 34.4 & 1582 & & 1.0 & 1.3 & 0.7 & 0.3 \\
\hline $4^{\prime}-t$-Butyl-2',6'-dimethylacetophenone & 34.5 & 1584 & & 1.4 & 2.8 & 0.7 & 0.7 \\
\hline Megastigmatrienone (isomer 3) & 34.9 & 1594 & & 1.6 & 1.7 & 1.5 & 0.1 \\
\hline Megastigmatrienone (isomer 4) & 35.4 & 1607 & & 7.3 & 10.8 & 2.5 & 3.1 \\
\hline 5-Isopropylidene-6-methyldeca-3,6,9-trien-2-one & 36.3 & 1631 & & 1.8 & 2.6 & 1.3 & 0.7 \\
\hline$\alpha$-Gurjunene & 36.3 & 1631 & 1404 & 3.8 & 7.5 & 1.9 & 3.2 \\
\hline Tetratetracontane & 38.4 & 1687 & & 1.7 & 2.5 & 1.1 & 0.7 \\
\hline Nonadecane (isomer 1) & 38.5 & 1689 & & 2.8 & 5.9 & 1.3 & 1.6 \\
\hline Heptadecane & 39.0 & 1703 & & 1.9 & 2.1 & 1.8 & 0.2 \\
\hline Nonadecane (isomer 2) & 44.6 & 1860 & & 2.0 & 3.1 & 1.1 & 0.7 \\
\hline
\end{tabular}

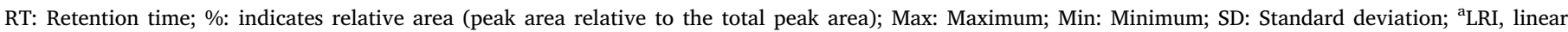

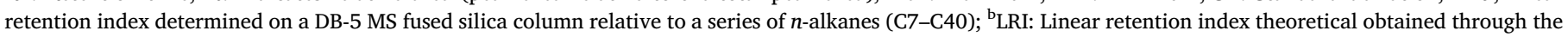
NIST Chemistry Web Book, SRD 69.

found in large concentrations in other heather honeys (de la Fuente et al., 2005; Castro-Vázquez et al., 2009; Castro-Vázquez, Alañón, Gonzalez-Viñas \& Pérez-Coello, 2012; Soria, Sanz \& Martínez-Castro, 2009).

Other compounds were also found in relevant concentrations, including cis-linalool oxide and phenylacetaldehyde. Like hotrienol, phenylacetaldehyde has been also detected at high concentrations in heather honeys (de la Fuente et al., 2005; Castro-Vázquez et al., 2009, 2012; Tan, Wilkins, Holland \& McGhie, 1989; Wolski, Tambor, Rybak-
Chmielewska \& Kedzia, 2006). The presence of both compounds in some honeys can be attributed to long-term storage or heat treatment. In these cases, and especially when the honey origin and production is unknown, the origin of these compounds is difficult to differentiate (Jerković \& Kuś, 2014). Phenylacetaldehyde is an aromatic hydrocarbon that can be produced in honey from the amino acid phenylalanine by enzymatic catalysis (Jerković \& Marijanović, 2010). Therefore, its content in unheated honey will depend on the content of phenylalanine, but also on the storage conditions (de la Fuente et al. 


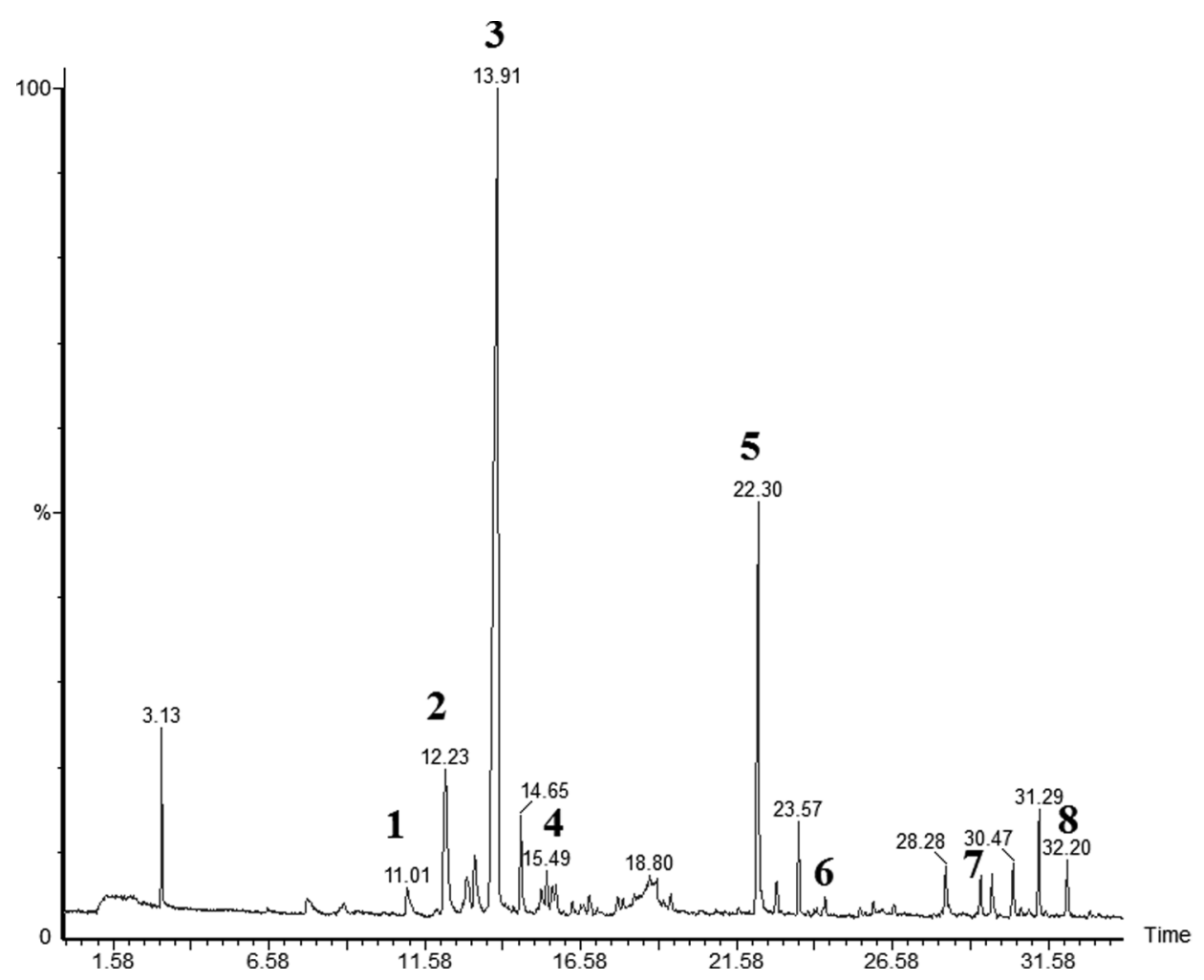

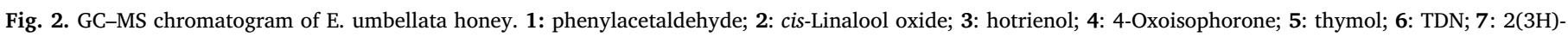
Furanone, 5-hexyldohydro-; 8: 3,7,7-trimethyl-1 penta-1,3-diphenyl-2 oxabicyclo[3,2,0]hept-3-ene.

2005). Compounds such as cis-linalool oxide have been previously found in the volatile profile of heather honeys (da Silva et al., 2016; Castro-Vázquez et al., 2009; Radovic et al., 2001) or honeydew honeys (Jerković \& Marijanović, 2010). On the other hand, some studies have linked the presence of these compounds with other sources rather than nectar, such as the hive atmospheres or the combustion of wood and biomass (Smith, Bromenshenk, Jones \& Alnasseer, 2002) during beekeeping activity.

The volatile profile of honey is a fingerprint that can be used together with the melissopalynological analysis to determine its botanical origin. As reported earlier (Radovic et al., 2001; Jerković \& Kuś, 2014), certain specific compounds are characteristic of honey from a specific floral source. In this regard, the frequency at which the compounds appear may be as important as their concentration, since they characterize the volatile profile and could be considered markers of heather honey. In the honeys under study, 3,7,7-trimethyl-1-penta-1,3-dienyl-2oxabicyclo [3.2.0] hept-3-ene stood out, appearing in $97 \%$ of the samples. This is a product derived from the breakdown of carotenoids (Siems, Salerno, Crifò, Sommerburg \& Wiswedel, 2009), with a probable plant origin, since it has been identified as a VOC in honeybush (Cylclopia subternata) (Roux, Cronje, Burger \& Joubert, 2012). Degraded carotenoids, such as 3,5,5-trimethylcyclohex-2-ene derivatives, were also detected in heather honeys from New Zealand, and are considered possible markers for these honeys (Soria et al., 2009; Tan et al., 1989).

In addition to hotrienol, phenylacetaldehyde and cis-linalool oxide are worth mentioning due to their frequency of appearance, which surpasses 50\%: 3-phenylfuran; $\delta$-decalactone; $\gamma$-decalactone; 1,1,5-trimethyl-1,2-dihydronaphthalene (TDN) and 4-oxoisophorone. Furan compounds (Castro-Vázquez et al. 2009; Wolski et al., 2006) and lactone derivatives such as $\gamma$-decalactone (Karabagias, Maia, Karabagias, Gatzias, \& Badeka, 2020), valerolactone (Guyot et al. 1999; Wolski et al., 2006), butyrolactone (Guyot et al. 1999), $\gamma$-butirrolactone (Radovic et al., 2001), and 4-oxoisophorone (de la Fuente et al., 2005; Soria et al., 2009; Wolski et al., 2006) have been previously described in heather honeys, and linked either with the presence of hexoses and pentoses or reactions of the shikimate pathway. On the other hand, naphthalene derivatives such as 1,1,5-trimethyl-1,2-dihydronapthalene or dihydro-trimethyl-naphthalene, although not previously associated with heather honey, have been observed in abundance in other honeys (Moniruzzaman, Rodríguez, Rodríguez-Cabo, Cela, Sulaiman \& Gan, 2014; Soria et al., 2009).

Some of the identified volatile compounds, although detected at a very low frequency, at least in two samples, have previously been described as part of the volatile composition of the plant origin or as aromatic compounds in other food products. Some were also identified in the volatile fraction of heather honey (de la Fuente et al., 2005; Wolski et al., 2006; Radovic et al., 2001), including methyl benzoate; 2phenylethanol; isophorone; ethylbenzoate; decanal; and 1-(2,6,6-trimethyl-1,3-cyclohexadien-1-yl)-2-buten-1-one. Compounds such as $\delta$ Selinene and 1,4-dimethyl-2-octadecylcyclohexane were found in concentrations less than or equal to $1 \%$.

\subsection{Volatile compounds according to the pollen profile}

The organoleptic characteristics and consequently the volatile composition of honey are closely associated with its botanical source (Manyi-Loh et al. 2011). The dominance of the different species in the honey studied depends, additionally, on the area of origin and the harvest season. Thus, although honey is generally referred to as heather honey, different types of heather honey can occur based on different species of Erica. The presence of one Erica species is accompanied by other frequent pollen types in the samples. Each of these honey samples can present different or common VOCs, depending on this botanical profile. The relationship between the main VOCs and the main pollen types was assessed using principal component analysis (Fig. 3). Through this analysis, a small number of linear combinations of 24 variables (the volatile compounds $\gamma$-decalactone; 4-methoxybenzaldehyde; 3-phenylfuran; decanoic acid, methyl ester; 1,7,7- 
Plot of Component Weights
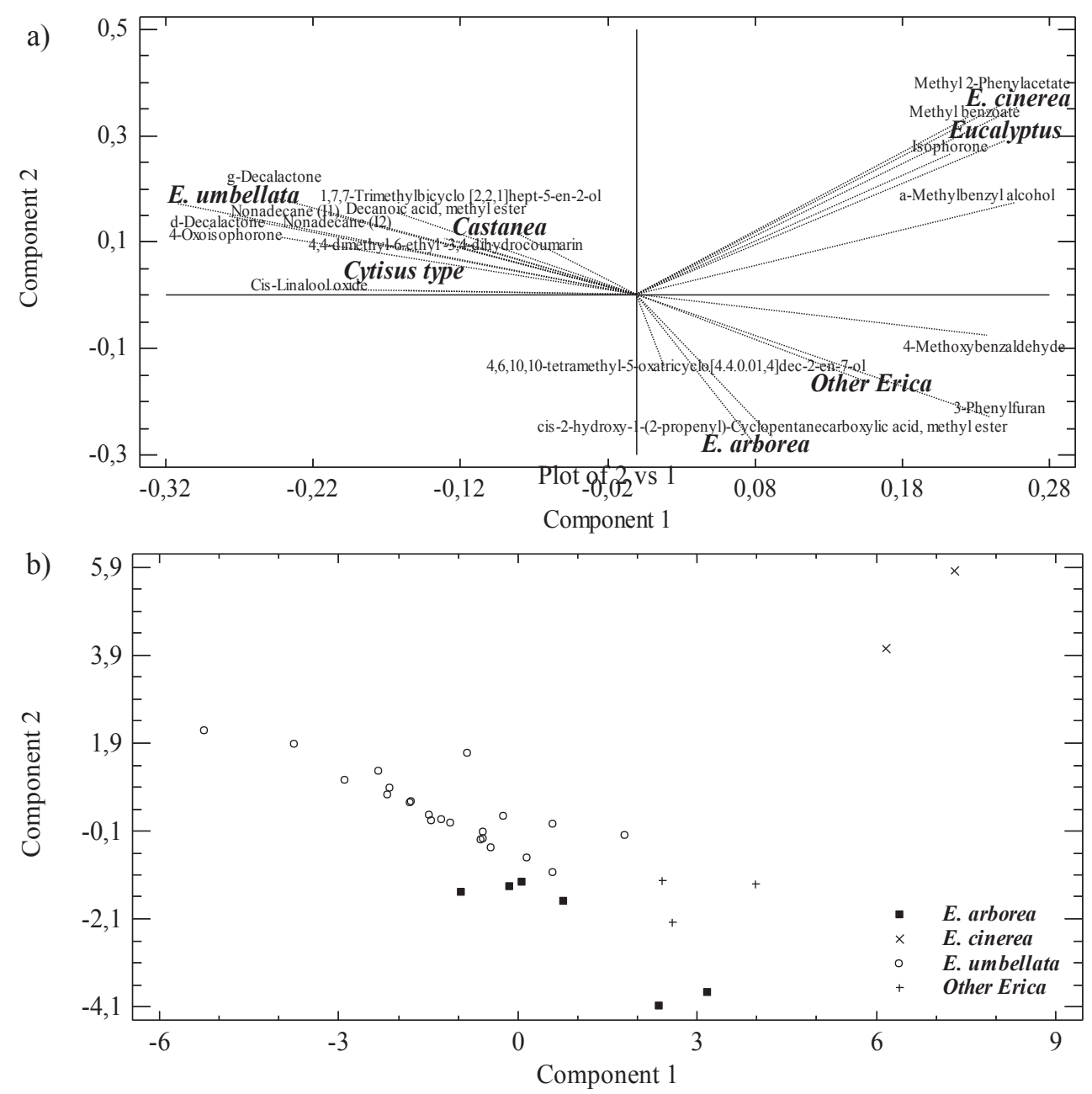

Fig. 3. The VOCs are represented in the upper figure according to the main pollen types. The graphical situation of the heather honey samples is shown in the figure below, depending on the predominance of the Erica species.

trimethylbicyclo [2,2,1]hept-5-en-2-ol; $\delta$-decalactone; 4,4-dimethyl-6ethyl-3,4-dihydrocoumarin; 4-oxoisophorone; 4,6,10,10-tetramethyl-5oxatricyclo[4.4.0.01,4] dec-2-en-7-ol; $\alpha$-methylbenzyl alcohol; methyl 2-phenylacetate; cis-Linalool oxide; cis-2-hydroxy-1-(2-propenyl)-Cyclopentanecarboxylic acid; methyl ester; isophorone; methyl benzoate; nonadecane (Isomer 1 and 2 ) and the main pollen types E. arborea; $E$. umbellata; E. cinerea; other Erica; Castanea; Cytisus type and Eucalyptus) were obtained, and these explain the variability of the data. In this case, seven components were separated. Together, they represent $81 \%$ of the variability in the original data. Fig. 3a shows the graphical representation of the first two components (43.3\% of the variability). The most influential variables for Component One were the VOCs 3-phenylfuran; 4-oxoisophorone; $\gamma$-decalactone; $\delta$-decalactone; and 4-oxoisophorone, and the pollen type E. umbellata. On the other hand, for Component Two they were the VOCs methyl 2-phenylacetate, methyl benzoate; and isophorone, and the pollen types Eucayptus and E. cinerea. At the other extreme of the same component, cis-2-hydroxy-1-(2-propenyl)-cyclopentanecarboxylic acid, methyl ester and 3-phenylfuran, and the pollen types E. arborea and other Erica, stood out.

The relationships among main pollen types and VOCs were checked using a Spearmańs rank correlation. Regarding the pollen type E. umbellata that appears in the space next to Castanea pollen, we found a positive correlation with nonadecane (Isomer 1 and 2) (Spearman's rank correlation $(\rho)$ of 0.571 with a $99.0 \%$ confidence level $(P<0.001)$ and 0.393 with a $95.0 \%$ confidence level $(P<0.05)$, respectively); $\gamma$-decalactone $(\rho=0.754 ; P<0.001) ; \delta$-decalactone ( $\rho=0.632 ; P<0.001) ; 1,7,7$-trimethylbicyclo [2,2,1] hept-5-en-2-ol, and 4,4-dimethyl-6-ethyl -3,4-dihydrocoumarin $(\rho=0.435$; $P<0.05)$ VOCs. E. cinerea showed positive correlations with $\alpha$-methylbenzyl alcohol $(\rho=0.364 ; P<0.05)$; methyl 2-phenylacetate $(\rho=0.480 ; P<0.001)$; isophorone; and methyl benzoate $(\rho=0.527$; $P<0.001)$, and the pollen type Eucalyptus $(\rho=0.419 ; P<0.01)$, which presented the same correlations with the previous compounds. $E$. arborea had positive correlations with 4,6,10,10-tetramethyl-5-oxatricyclo[4.4.0.01,4]dec-2-en-7-ol $(\rho=0.482 ; P<0.001)$ and cis-2hydroxy-1-(2-propenyl)-cyclopentanecarboxylic acid, methyl ester $(\rho=0.387 ; P<0.001)$. The group formed by other Erica showed positive correlations with 4-methoxybenzaldehyde $(\rho=0.388$; $P<0.05)$ and 3-phenylfuran $(\rho=0.455 ; P<0.001)$. Finally, the pollen type Cytisus was related with decanoic acid, methyl ester ( $\rho=0.399 ; P<0.05)$; 4-oxoisophorone $(\rho=0.432 ; P<0.05)$; and cis-linalool oxide $(\rho=0.589 ; P<0.001)$, along with Eucalyptus.

Fig. $3 \mathrm{~b}$ represents the samples considering the values of the two first components, and depending on the predominance of the Erica species. It can be observed that samples were located according to the main pollen types and the VOCs with which they were correlated. Some of them, in which E. umbellata predominates, and others with a predominance of $E$. arborea, are very close. Both species can grow together, sharing the plant communities, therefore the nectar of both plants can be present in the same honey. On the other hand, the samples of $E$. 
cinerea are further apart, showing the influence of other factors, such as the presence of Eucalyptus. As a result of the PCA, the pollen profile of samples helps us to understand the variability of the data, so this information plays a very important role in the study of VOCs in honey.

Some of the identified compounds in the samples have already been associated with certain botanical origins in honey. Nonadecane has been found in thyme honey from Greece (Alissandrakis, Tarantilis, Pappas, Harizanis \& Polissiou, 2009), 2,3-dihydrobenzofuran in sage (Salvia officinalis) honey (Jerković, Mastelić \& Marijanović, 2006), $\gamma$ decalactone in quince tree honey (Moreira, Trugo, Pietroluongo \& De Maria, 2002) and in heather honey from Portugal (Karabagias et al. 2020), and thymol in Thymus capitatus honey (Kaškoniene \& Venskutonis, 2010). The large amount of this latter compound may also point to the use of this substance by beekeepers as an acaricide in the sanitary control of the varroa mite (Bogdanov 2006). For E. arborea honey some authors, such as Guyot et al. (1999), have proposed some volatiles as markers; namely, 4-hydroxy-3-methoxybenzoate methyl ester (methyl vanillate); 4-methoxybenzaldehyde ( $p$-anisaldehyde); and 4-methoxybenzoic acid ( $p$-anisic acid). Other authors (Yang, Battesti, Paolini, Muselli, Tomi \& Costa, 2012) have confirmed the presence of 4propylanisol, $p$-anisaldehyde, benzaldehyde, and 3-furaldehyde as volatile compounds dominant in ' $E$. arborea spring maquiś honeys. In this study, $p$-anisaldehyde was found as a volatile compound in six samples of E. arborea. However, this compound also appeared in E. cinerea and other Erica samples. Castro-Vázquez et al. (2009) and (2012) found this compound in heather honey, along with other compounds of the same nature such as guaiacol, propylanisole, and p-cresol. In the case of methyl 2-phenylacetate, although it has been identified in heather honey (Wolski et al. 2006), it has also been identified in the volatile profile of sage honey and in multifloral honey (Wolski et al., 2006; Kaškonienè \& Venskutonis, 2010).

The number of shared VOCs in all samples was low (Table 3). From the identified compounds, seven were common to all the samples studied: phenylacetaldehyde; 3-phenylfuran; isophorone; 1,1,5-trimethyl1,2-dihydronaphthalene; 1-(2,6,6-trimethyl-1,3-cyclohexadien-1-yl)-2- buten-1-one; 1,1,6-trimethyl-1,2-dihydronaphthalene and 3,7,7-trimethyl-1-penta-1,3-dienyl-2-oxabicyclo[3.2.0]hept-3-ene. Table 3 also shows 20 VOCS that only appeared in heather honey samples with $E$. umbellata; $\gamma$-decalactone stood out, and one compound occurred in heather honey samples with $E$. cinerea and E, arborea; cis-2-hydroxy-1(2-propenyl)-cyclopentanecarboxylic acid, methyl ester and methyl 2phenylacetate, respectively.

Some of these compounds, such as phenylacetaldehyde; 3-phenylfuran; isophorone and 1-(2,6,6-trimethyl-1,3-cyclohexadien-1-yl)-2buten-1-one, have been attributed to heather honey in other studies (Boi, Llorens, Cortés, Lladó, \& Llorens, 2013; Castro-Vázquez et al., 2009; de la Fuente et al., 2005; Guyot et al., 1999; Plutowska, Chmiel, Dymerski \& Wardencki, 2011; Soria et al., 2009; Radovic et al., 2001; Tan et al., 1989; Wolski et al., 2006). In addition to these compounds, other VOCs identified in this study have been found in samples of heather honey of the Erica genus. The main compounds were hotrienol (Castro-Vázquez et al., 2009; de la Fuente et al., 2005; Karabagias et al., 2018; Soria et al., 2009) and linalool oxide (Boi et al., 2013; de la Fuente et al., 2005; Karabagias et al., 2018; Radovic et al., 2001; Soria et al., 2009; Wolski et al., 2006), and in lower amounts 2-phenylethanol (Castro-Vázquez et al., 2009; de la Fuente et al., 2005; Guyot et al., 1999; Soria et al., 2009; Tan et al., 1989); 4-methoxybenzaldehyde (panisaldehyde) (Castro-Vázquez et al., 2009; Guyot et al., 1999); 4-oxoisophorone (Boi et al., 2013; de la Fuente et al., 2005; Radovic et al., 2001; Soria et al., 2009; Tan et al., 1989; Wolski et al., 2006); decanal (Radovic et al., 2001; Wolski et al. 2006); decanoic acid (Guyot et al. 1999); ethylbenzoate (de la Fuente et al., 2005; Radovic et al., 2001); $\gamma$ decalactone (Karabagias et al. 2018); methyl benzoate (Tan et al.1989); and safranal (Boi et al. 2013). However, other compounds have been found in the literature, different from those in this study, which could demonstrate that the Erica species, together with the associated flora, determine the VOCs. Some of the most discussed are 1-hexanol (CastroVázquez et al., 2009; de la Fuente et al., 2005; Radovic et al., 2001); 2Furanmethanol (Castro-Vázquez et al., 2009; de la Fuente et al., 2005; Wolski et al., 2006); 3-methyl-1-butanol (de la Fuente et al., 2005;

Table 3

VOCs present in samples regarding the main Erica species.

\begin{tabular}{|c|c|c|c|c|c|c|c|c|c|c|c|c|}
\hline \multirow[t]{2}{*}{ Volatile compounds } & \multicolumn{3}{|c|}{ E. arborea } & \multicolumn{3}{|c|}{ E. cinerea } & \multicolumn{3}{|c|}{ E. umbellata } & \multicolumn{3}{|c|}{ Other Erica } \\
\hline & Mean & Range & SD & Mean & Range & SD & Mean & Range & SD & Mean & Range & SD \\
\hline 1,1,5-trimethyl-1,2-dihydronaphthalene (TDN) & 6.6 & $16.5-1.8$ & 6.3 & 19.2 & $19.6-1.8$ & 0.6 & 1.8 & $12.0-0.0$ & 3.1 & 15.4 & $20.9-8.4$ & 6.4 \\
\hline Phenylacetaldehyde & 6.4 & $15.80-0.0$ & 6.6 & 16.4 & $17.1-15.7$ & 1.0 & 4.1 & $37.0-0.0$ & 8.6 & 15.0 & $29.4-0.0$ & 14.7 \\
\hline Isophorone & 0.3 & $1.7-0.0$ & 0.7 & 5.7 & $7.5-3.8$ & 2.6 & 0.5 & $8.3-0.0$ & 1.8 & 2.0 & $3.0-0.0$ & 1.7 \\
\hline 3,7,7-Trimethyl-1-penta-1,3-dienyl-2-oxabicyclo[3.2.0]hept-3-ene & 5.8 & $12.0-1.9$ & 3.9 & 4.9 & $7.0-2.8$ & 2.9 & 4.4 & $11.5-0.0$ & 3.3 & 12.9 & $26.2-3.8$ & 11.8 \\
\hline 3-Phenylfuran & 4.3 & $10.7-0.0$ & 4.4 & 3.5 & $3.6-3.4$ & 0.2 & 2.1 & $7.2-0.0$ & 2.0 & 5.2 & $7.4-3.7$ & 1.9 \\
\hline 1-(2,6,6-trimethyl-1,3-cyclohexadien-1-yl)-2-buten-1-one & 1.7 & $5.4-0.0$ & 2.2 & 2.6 & $2.8-2.5$ & 0.2 & 0.2 & $2.5-0.0$ & 0.6 & 1.1 & $2.2-0.0$ & 1.1 \\
\hline 1,1,6-Trimethyl-1,2-dihydronaphthalene & 1.6 & $5.3-0.0$ & 2.5 & 1.4 & $1.4-1.3$ & 0.1 & 0.1 & $2.5-0.0$ & 0.5 & 1.4 & $2.0-0.8$ & 0.6 \\
\hline 1,4-dimethyl-2-octadecylcyclohexane & - & - & - & - & - & - & 0.07 & $1.0-0.0$ & 0.2 & - & - & - \\
\hline 1,7,7-Trimethylbicyclo $[2,2,1]$ hept-5-en-2-ol & - & - & - & - & - & - & 1.3 & $8.5-0.0$ & 2.8 & - & - & - \\
\hline 2,3-Dihydrobenzofuran & - & - & - & - & - & - & 2.2 & $10.4-0.0$ & 3.3 & - & - & - \\
\hline 4,4-dimethyl-6-ethyl -3,4-dihydrocoumarin & - & - & - & - & - & - & 0.14 & $1.3-0.0$ & 0.4 & - & - & - \\
\hline 2,6-dimethyl-3,7-octadiene-2,6-diol & - & - & - & - & - & - & 0.5 & $8.1-0.0$ & 1.8 & - & - & - \\
\hline $4^{\prime}-t$-Butyl-2',6'-dimethylacetophenone & - & - & - & - & - & - & 0.4 & $2.8-0.0$ & 0.8 & - & - & - \\
\hline 5-Isopropylidene-6-methyldeca-3,6,9-trien-2-one & - & - & - & - & - & - & 0.2 & $2.6-0.0$ & 0.7 & - & - & - \\
\hline 5-Methyl-2-phenyl-2-hexenal & - & - & - & - & - & - & 0.09 & $1.4-0.0$ & 0.3 & - & - & - \\
\hline Ethyl decanoate & - & - & - & - & - & - & 0.3 & $2.8-0.0$ & 0.8 & - & - & - \\
\hline Ethyl isoallocholate & - & - & - & - & - & - & 0.11 & $1.4-0.0$ & 0.4 & - & - & - \\
\hline$\gamma$-Decalactone & - & - & - & - & - & - & 4.6 & $13.0-0.0$ & 3.5 & - & - & - \\
\hline Heptadecane & - & - & - & - & - & - & 0.2 & $2.1-0.0$ & 0.6 & - & - & - \\
\hline Decanoic acid, methyl ester & - & - & - & - & - & - & 0.4 & $6.5-0.0$ & 1.5 & - & - & - \\
\hline$n$-Decanoic acid & - & - & - & - & - & - & 0.6 & $5.7-0.0$ & 1.6 & - & - & - \\
\hline Nonadecane (isomer 1) & - & - & - & - & - & - & 1.0 & $5.9-0.0$ & 1.7 & - & - & - \\
\hline Nonadecane (isomer 2) & - & - & - & - & - & - & 0.9 & $3.1-0.0$ & 1.1 & - & - & - \\
\hline Pentadecane & - & - & - & - & - & - & 0.09 & $1.3-0.0$ & 0.3 & - & - & - \\
\hline Tetradecane & - & - & - & - & - & - & 0.2 & $2.2-0.0$ & 0.5 & - & - & - \\
\hline Tetratetracontane & - & - & - & - & - & - & 0.2 & $2.5-0.0$ & 0.6 & - & - & - \\
\hline Thymol & - & - & - & - & - & - & 1.7 & $14.7-0.0$ & 3.3 & - & - & - \\
\hline cis-2-hydroxy-1-(2-propenyl)-Cyclopentanecarboxylic acid, methyl ester & 2.3 & $9.2-0.0$ & 3.8 & - & - & - & - & - & - & - & - & - \\
\hline Methyl 2-Phenylacetate & - & - & - & 4.3 & $5.6-3.0$ & 1.9 & - & - & - & - & - & - \\
\hline
\end{tabular}


Guyot et al., 1999; Radovic et al., 2001); 3-methyl-3-buten-1-ol (de la Fuente et al., 2005; Guyot et al., 1999; Soria et al., 2009; Radovic et al., 2001); acetoin (de la Fuente et al., 2005; Guyot et al., 1999; Radovic et al., 2001); benzaldehyde (Castro-Vázquez et al., 2009; de la Fuente et al., 2005; Guyot et al., 1999; Karabagias et al., 2018; Tan et al., 1989; Soria et al., 2009; Wolski et al., 2006); benzoic acid (Castro-Vázquez et al., 2009; Guyot et al., 1999; Plutowska et al., 2011); benzyl alcohol (Castro-Vázquez et al., 2009; de la Fuente et al., 2005; Radovic et al., 2001; Soria et al., 2009; Tan et al., 1989; Wolski et al. 2006); lilac aldehyde (Castro-Vázquez et al., 2009; de la Fuente et al., 2005and Wolski et al., 2006); and octanoic acid (Castro-Vázquez et al., 2009; Guyot et al., 1999; Wolski et al., 2006).

\section{Conclusions}

The analysis of volatile compounds using solid-phase microextraction (SPME) and GC-MS was successful in identifying the volatile profile of heather honey. The main compounds found in this honey were terpenoids, alcohols, benzene compounds, furan derivatives, and aldehydes. Hotrienol could be a clear marker for all heather honey, either due to its presence regardless of the Erica species or due to the high concentration observed on the volatile profile. Phenylacetaldehyde and cis-linalool oxide were also very abundant and frequent volatile compounds in all samples.

The correlations found between the pollen types of the palynological spectrum of the samples and the presence of certain volatile compounds reinforces the dependence of these compounds on the botanical origin of honey. In this sense, the dominance of the Erica species and the associated flora in the samples involved a specific volatile compound profile.

\section{CRediT authorship contribution statement}

M. Shantal Rodríguez-Flores: Conceptualization, Methodology, Data curation, Writing - original draft, Software, Validation, Writing review \& editing. Soraia I. Falcão: Conceptualization, Methodology, Software, Validation, Writing - review \& editing. Olga Escuredo: Supervision, Writing - review \& editing. M. Carmen Seijo: Visualization, Investigation, Supervision, Writing - review \& editing. Miguel Vilas-Boas: Conceptualization, Methodology, Visualization, Investigation, Writing - review \& editing.

\section{Declaration of Competing Interest}

The authors declare that they have no known competing financial interests or personal relationships that could have appeared to influence the work reported in this paper.

\section{Acknowledgements}

The authors would like to thank the Fundação para a Ciência e Tecnologia (FCT, Portugal) for the financial support by national funds FCT/MCTES to CIMO (UIDB/00690/2020). S. I. Falcão thanks for the national funding provided by FCT-Foundation for Science and Technology, through the institutional scientific employment programcontract.

\section{References}

Alissandrakis, E., Tarantilis, P. A., Pappas, C., Harizanis, P. C., \& Polissiou, M. (2009). Ultrasound-assisted extraction gas chromatography-mass spectrometry analysis of volatile compounds in unifloral thyme honey from Greece. European Food Research and Technology, 229(3), 365-373.

Arthur, C. L., \& Pawliszyn, J. (1990). Solid phase microextraction with thermal desorption using fused silica optical fibers. Analytical chemistry, 62(19), 2145-2148. Bogdanov, S. (2006). Contaminants of bee products. Apidologie, 37(1), 1-18.

Boi, M., Llorens, J. A., Cortés, L., Lladó, G., \& Llorens, L. (2013). Palynological and chemical volatile components of typically autumnal honeys of the western Mediterranean. Grana, 52(2), 93-105.

Castro-Vázquez, L., Díaz-Maroto, M. C., De Torres, C., \& Pérez-Coello, M. S. (2010). Effect of geographical origin on the chemical and sensory characteristics of chestnut honeys. Food Research International, 43(10), 2335-2340.

Castro-Vázquez, L., Díaz-Maroto, M. C., González-Viñas, M. A., \& Pérez-Coello, M. S (2009). Differentiation of monofloral citrus, rosemary, eucalyptus, lavender, thyme and heather honeys based on volatile composition and sensory descriptive analysis. Food Chemistry, 112(4), 1022-1030.

Castro-Vázquez, L., Alañon, M. E., Gonzalez-Viñas, M. A., \& Pérez-Coello, M. S. (2012). Changes in the volatile fractions and sensory properties of heather honey during storage under different temperatures. European Food Research and Technology, 235(2), 185-193.

Cuevas-Glory, L. F., Pino, J. A., Santiago, L. S., \& Sauri-Duch, E. (2007). A review of volatile analytical methods for determining the botanical origin of honey. Food Chemistry, 103(3), 1032-1043.

da Silva, P. M., Gauche, C., Gonzaga, L. V., Costa, A. C. O., \& Fett, R. (2016). Honey: Chemical composition, stability and authenticity. Food Chemistry, 196, 309-323.

de la Fuente, E., Martínez-Castro, I., \& Sanz, J. (2005). Characterization of Spanish unifloral honeys by solid phase microextraction and gas chromatography-mass spectrometry. Journal of Separation Science, 28(9-10), 1093-1100.

Escuredo, O., Dobre, I., Fernández-González, M., \& Seijo, M. C. (2014). Contribution of botanical origin and sugar composition of honeys on the crystallization phenomenon. Food Chemistry, 149, 84-90.

Escuredo, O., Fernández-González, M., \& Seijo, M. C. (2012). Differentiation of blossom honey and honeydew honey from Northwest Spain. Agriculture, 2(1), 25-37.

Escuredo, O., Míguez, M., Fernández-González, M., \& Seijo, M. C. (2013). Nutritional value and antioxidant activity of honeys produced in a European Atlantic area. Food Chemistry, 138(2-3), 851-856.

Guyot, C., Scheirman, V., \& Collin, S. (1999). Floral origin markers of heather honeys: Calluna vulgaris and Erica arborea. Food Chemistry, 64(1), 3-11.

Jerković, I., \& Kuś, P. M. (2014). Terpenes in honey: Occurrence, origin and their role as chemical biomarkers. RSC Advances, 4(60), 31710-31728.

Jerković, I., \& Marijanović, Z. (2010). Oak (Quercus frainetto Ten.) honeydew honey-Approach to screening of volatile organic composition and antioxidant capacity (DPPH and FRAP assay). Molecules, 15(5), 3744-3756.

Jerković, I., Mastelić, J., \& Marijanović, Z. (2006). A variety of volatile compounds as markers in unifloral honey from Dalmatian sage (Salvia officinalis L.). Chemistry \& Biodiversity, 3(12), 1307-1316.

Karabagias, I. K., Maia, M., Karabagias, V. K., Gatzias, I., \& Badeka, A. V. (2018). Characterization of eucalyptus, chestnut and heather honeys from Portugal using multi-parameter analysis and chemo-calculus. Foods, 7(12), 194.

Karabagias, I. K., Papastephanou, C., \& Karabagias, V. K. (2019). Geographical differentiation of Cypriot multifloral honeys through specific volatile compounds and the use of DFA. AIMS Agriculture and Food, 4(1), 149-162.

Karabagias, I. K., Maia, M., Karabagias, V. K., Gatzias, I., \& Badeka, A. V. (2020). Quality and origin characterisation of Portuguese, Greek, Oceanian, and Asian honey, based on poly-parametric analysis hand in hand with dimension reduction and classification techniques. European Food Research and Technology, 1-20.

Kaškoniene, V., \& Venskutonis, P. R. (2010). Floral markers in honey of various botanical and geographic origins: A review. Comprehensive Reviews in Food Science and Food Safety, 9(6), 620-634.

Manyi-Loh, C. E., Ndip, R. N., \& Clarke, A. M. (2011). Volatile compounds in honey: A review on their involvement in aroma, botanical origin determination and potential biomedical activities. International Journal of Molecular Sciences, 12(12), 9514-9532.

Moniruzzaman, M., Rodríguez, I., Rodríguez-Cabo, T., Cela, R., Sulaiman, S. A., \& Gan, S. H. (2014). Assessment of dispersive liquid - liquid microextraction conditions for gas chromatography time-of-flight mass spectrometry identification of organic compounds in honey. Journal of Chromatography A, 1368, 26-36.

Moreira, R. F. A., Trugo, L. C., Pietroluongo, M., \& De Maria, C. A. B. (2002). Flavor composition of cashew (Anacardium occidentale) and marmeleiro (Croton species) honeys. Journal of Agricultural and Food Chemistry, 50(26), 7616-7621.

Persano-Oddo, L., Piro, R., Bruneau, É., Guyot-Declerck, C., Ivanov, T., Piskulová, J., \& Von der Ohe, W. (2004). Main European unifloral honeys: Descriptive sheets. Apidologie, 35(Suppl. 1), S38-S81.

Piasenzotto, L., Gracco, L., \& Conte, L. (2003). Solid phase microextraction (SPME) applied to honey quality control. Journal of the Science of Food and Agriculture, 83(10), 1037-1044.

Plutowska, B., Chmiel, T., Dymerski, T., \& Wardencki, W. (2011). A headspace solidphase microextraction method development and its application in the determination of volatiles in honeys by gas chromatography. Food Chemistry, 126(3), 1288-1298.

Radovic, B. S., Careri, M., Mangia, A., Musci, M., Gerboles, M., \& Anklam, E. (2001). Contribution of dynamic headspace GC-MS analysis of aroma compounds to authenticity testing of honey. Food Chemistry, 72(4), 511-520.

Rodríguez-Flores, M. S., Escuredo, O., Seijo-Rodríguez, A., \& Seijo, M. C. (2019). Characterization of the honey produced in heather communities (NW Spain). Journal of Apicultural Research, 58(1), 84-91.

Roux, M. L., Cronje, J. C., Burger, B. V., \& Joubert, E. (2012). Characterization of volatiles and aroma-active compounds in honeybush (Cyclopia subternata) by GC-MS and GCO analysis. Journal of Agricultural and Food Chemistry, 60(10), 2657-2664.

Seijo, M. C., \& Jato, M. V. (1998). Palynological characterization of honeys from Galicia (Northwest Spain). Grana, 37(5), 285-292.

Siems, W., Salerno, C., Crifò, C., Sommerburg, O., \& Wiswedel, I. (2009). B-Carotene degradation products-formation, toxicity and prevention of toxicity. Food Factors for Health Promotion, 61, 75-86.

Smith, G. C., Bromenshenk, J. J., Jones, D. C., \& Alnasseer, G. H. (2002). Volatile and 
semivolatile organic compounds in beehive atmospheres. In J. Devillers, \& M. H. Pham-Delègue (Eds.). Honey Bees: Estimating the Environmental Impact of Chemicals (pp. 12-41). London and New York: Taylor and Francis.

Soria, A. C., Sanz, J., \& Martínez-Castro, I. (2009). SPME followed by GC-MS: A powerful technique for qualitative analysis of honey volatiles. European Food Research and Technology, 228(4), 579-590.

Tan, S. T., Wilkins, A. L., Holland, P. T., \& McGhie, T. K. (1989). Extractives from New Zealand unifloral honeys. 2. Degraded carotenoids and other substances from heather honey. Journal of Agricultural and Food Chemistry, 37(5), 1217-1221.
Tuberoso, C. I., Bifulco, E., Caboni, P., Cottiglia, F., Cabras, P., \& Floris, I. (2009). Floral markers of strawberry tree (Arbutus unedo L.) honey. Journal of Agricultural and Food Chemistry, 58(1), 384-389.

Wolski, T., Tambor, K., Rybak-Chmielewska, H., \& Kedzia, B. (2006). Identification of honey volatile components by solid phase microextraction (SPME) and gas chromatography/mass spectrometry (GC/MS). Journal of Apicultural Science, 50(2), 115-126.

Yang, Y., Battesti, M. J., Paolini, J., Muselli, A., Tomi, P., \& Costa, J. (2012) Melissopalynological origin determination and volatile composition analysis of Corsican "Erica arborea spring maquis" honeys. Food Chemistry, 134(1), 37-47. 